\title{
Attachment and Academic Classroom Behavior: Self-Efficacy and Procrastination as Moderators on the Influence of Attachment on Academic Success
}

\author{
Robert M. Kurland, Harold I. Siegel \\ Department of Psychology, Rutgers University-Newark, New Jersey, USA \\ Email: rmkurland@gmail.com
}

Received 16 April 2016; accepted 11 July 2016; published 14 July 2016

Copyright (C) 2016 by authors and Scientific Research Publishing Inc.

This work is licensed under the Creative Commons Attribution International License (CC BY). http://creativecommons.org/licenses/by/4.0/

\section{(c) (i) Open Access}

\begin{abstract}
Attachment, self-efficacy, and procrastination were measured in 161 college students enrolled in an Introductory Psychology class. Class grades and overall academic records were also obtained. Students who had higher levels of attachment anxiety had lower final grades in the class, higher levels of procrastination, and lower self-efficacy. Students with higher levels of attachment avoidance had lower grades within the class and a lower overall Grade Point Average (GPA). Regression analysis showed that self-efficacy moderated the relationship between attachment and class grade as well as overall GPA. Procrastination also moderated the relationship between both attachment anxiety and GPA and attachment avoidance and GPA.
\end{abstract}

\section{Keywords}

Attachment, Procrastination, Self-Efficacy, Academic Success

\section{Introduction}

A number of psychological factors affect college academic success including: motivation (Linnenbrink \& Pintrich, 2002), emotional intelligence (Parker, Summerfeldt, Hogan, \& Majeski, 2004), attitude (Tracey \& Sedlacek, 1985), exploration (Aspelmeier \& Kerns, 2003), persistency (Larose, Bernier, \& Tarabulsy, 2005), selfconfidence (Mattanah, Hancock, \& Brand, 2004), academic achievement (Fass \& Tubman, 2002) and social competency (Bernier, Larose, Boivin, \& Soucy, 2004), and self-esteem (Brennan \& Morris, 1997). Many of these factors are closely related to attachment security. According to Mikulincer and Shaver (2007), a successful 
student "requires cognitive openness, self-control, positive attitudes toward learning and problem solving, optimistic expectations of academic success, and constructive ways of coping with frustrations and failures" (p. 237). Secure individuals tend to possess these self-regulatory skills and have been shown to better handle stress (Salas, Driskell, \& Hughes, 1996), have higher-levels of self-confidence and self-esteem (Mattanah, Hancock, \& Brand, 2004; Brennan \& Morris, 1997), have better academic competency (Fass \& Tubman, 2002), and more successfully transition from high school to college (Kurland \& Siegel, 2013).

This study examined two specific factors that can be observed in the classroom and are related to both attachment and academic success: self-efficacy (Cutrona, Cole, Colangelo, Assouline, \& Russell, 1994) and procrastination (Hazan \& Shaver, 1990). By examining these factors within the classroom, one may be able to better predict academic success and intervene appropriately when necessary.

\section{Self-Efficacy}

Self-efficacy has been defined as one's evaluation of his or her own ability or competency to achieve a goal, perform a task, or overcome an obstacle (Bandura, 1986). A person's self-efficacy is formed by an assortment of experiences including one's perception of own ability, feedback from others, social competence, and self-assessment (Schunk \& Pajares, 2002). If a person does not believe that he/she can achieve a goal, then he/she will have little incentive to do so. Therefore, one's belief that he/she can be successful will have a direct impact on actual successes and failures. The impact of self-efficacy can be seen in a wide range of areas including politics, sports, and relationships (Baron \& Byrne, 2003). Research on self-efficacy has also been shown to be related to performance on both physical_(Courneya \& McAuley, 1993)_and academic tasks (Sanna \& Pusecker, 1994).

From an academic perspective, self-efficacy affects students' ability to complete coursework, regulate learning, and live up to the academic expectations of themselves and others (Baron \& Byrne, 2003). While academic success in grade school may be more attributed to teachers' close monitoring of students' work and progress, as students advance through their academic careers and teachers become less involved in an individual's learning process (e.g., at college), levels of self-efficacy become more important. In an academic environment, self-efficacy beliefs tend to influence effort, persistence, task choice, resilience, and achievement (Schunk, 1995). Often individuals who are low in self-efficacy tend to worry about negative events and attribute them to external factors (Myers, 1989), e.g., a perceived "bad" teacher or being subjected to an "unfair" exam. On the contrary, a student high in self-efficacy will attribute one's successes and/or failures to his or her own abilities. Self-efficacy has been shown to be highly correlated with academic achievement (Bandura, 1997; Pajares, \& Schunk, 2001; Schunk, 1995). Research has shown that students with high self-efficacy with problem solving are more persistent than students with low-self-efficacy (Bouffard-Bouchard, Parent, \& Larivee, 1991). Students who have high self-efficacy in writing proficiency also have been shown to have high levels of academic success (Zimmerman \& Bandura, 1994). Mathematics self-efficacy has been shown to be a better predictor of mathematics achievement compared to any other factor including math anxiety, self-concept, or even prior experience with math (Pajares \& Miller, 1994).

Aspects of self-efficacy and attachment theory share similarities. Both attachment and self-efficacy develop early in life. A stimulating environment allows children to explore, develop mastery experiences, and help build self-efficacy. When an environment contains stimulating experiences, children will explore and learn to navigate through these challenges and thus develop new skills and abilities (Meece, 1997). As one works on a task, he or she learns what a desirable action is and is thus motivated to persist and achieve, thus increasing one's self-efficacy. Similarly, one of the main aspects of attachment security involves exploration (Ainsworth, Blehar, Waters, \& Wall, 1978); not surprisingly, research has shown secure individuals tend to explore more. Individuals who are more competent and effective would be more willing to explore and risk failure. By creating an environment in which children feel more comfortable to explore (secure attachment), children are able to further develop mastery of their environment while learning new skills and thus increasing their own self-efficacy. Furthermore, individuals who have high self-efficacy are less depressed, less anxious, and more persistent (Maddux \& Stanley, 1986), all qualities that parallel those of a securely attached individual.

Research involving attachment and self-efficacy has covered topics ranging from leadership, conflict resolution, depression, and social support. In one study on leadership, Davidovitz, Mikulincer, Shaver, Ijzak, and Popper (2007) assessed participants' self-reported ability to be successful. They were interested in how individuals perceived their ability to meet both task and emotional needs of their followers. Individuals high in attachment 
anxiety scored lower in self-efficacy on task-forced situations while individuals high on attachment avoidance scored lower in self-efficacy on emotional related situations. In another study, Corcoran and Mallinckrodt (2000) examined the influence of self-efficacy as it related to attachment style and conflict resolution. Self-efficacy helped to explain the relationship between attachment security and compromising and integrating styles of conflict resolution. In addition, self-efficacy mediated the relationship between attachment avoidance and approaches to conflict resolution.

Through a longitudinal study, Wei, Russell, and Zakalik (2005) examined the influence of self-efficacy and attachment as it related to feelings of loneliness and depression. In this study, students were asked to complete a series of surveys measuring attachment, self-efficacy, self-confidence, depression, and loneliness. The surveys were completed in both of their first two semesters (October and March, respectively) of their freshman year. The results showed that self-efficacy did indeed serve as a mediator between attachment anxiety and feelings of depression and loneliness; 55\% of the variance in loneliness was attributed to attachment anxiety, self-efficacy, and self-disclosure. Mallinckrodt and Wei (2005) examined the effect of self-efficacy as it related to the relationship between attachment and psychological distress and perceived social support. Social self-efficacy was a significant mediator for both attachment anxiety and attachment avoidance.

\section{Procrastination}

Procrastination, or one's tendency to delay or postpone, is a specific behavior that can be measured within the classroom. As time management and planning are prevalent topics for academic success centers and freshman seminar courses within higher education, it is apparent that procrastination is a major concern/obstacle for college students. Research on procrastination and academic success has shown that students who procrastinate have higher rates of course withdrawals, lower academic performance, and poorer health (Pychyl, Morin, \& Salmon, 2000). One specific study on academic success involved the effect of procrastination on mathematics achievement. Akinsola, Tella, and Tella (2007) used a thirty-five item academic procrastination scale with a group of 150 students. The data were analyzed in conjunction with each student's grades from their mathematics courses and showed a significant negative correlation between academic procrastination and achievement in mathematics $(r=.183, p=.032)$. In addition, according to Klassen, Krawchuk, and Rajani (2008), students who were classified as high procrastinators had lower GPAs, lower class grades and lower levels of self-efficacy for self-regulation. Furthermore, after controlling for GPA, self-efficacy predicted the negative impact of procrastination.

While there is not extensive research involving attachment and procrastination, it is likely that a relationship does exist. According to Mikulincer and Shaver (2007), individuals who score higher on attachment avoidance and/or attachment anxiety tended to score lower on tasks including problem solving, task concentration and persistence, and behavioral reorganization. Additionally, they received higher scores on procrastination. In fact, according to Burka and Yuen (1983), procrastination can be seen as a way of creating a barrier between oneself and others and can be seen in both avoidant and anxious individuals within a variety of decision-making situations.

Individuals who are high in attachment anxiety are characterized as having a negative view of self and therefore may be unsure about their own abilities and actions. This uncertainty may in turn cause them to delay (or procrastinate) any decisions they may make due to fear of making a wrong decision and thus further alienating themselves from others by not fitting in. They may also delay performing activities and making decisions if the activity or decision will cause a separation from an attachment figure. Procrastination can also be seen in relationships as insecure anxious individuals may delay ending a relationship because they are uncomfortable being alone (Bartholomew \& Horowitz, 1991). This tendency to procrastinate is also quite prevalent in academia as the activity may range from a simple matter such as working on a homework assignment to choosing which college to attend. They may also procrastinate in terms of their studies to avoid another transitional experience as they move on to the real world and face further independence which could cause further separation anxiety.

Other research has shown that procrastination is associated with avoidant attachment (Skowron \& Dendy, 2004). Avoidant individuals have a negative view of others, and they may therefore procrastinate to avoid possible scrutiny by others. Procrastination can also be clearly seen in regards to relationships as avoidants may also delay entering into a relationship with the fear of allowing themselves to be close to another. Simultaneously, avoidants may procrastinate with work as an excuse that they cannot be involved in a relationship because they 
have too many things that they need to accomplish (Hazan \& Shaver, 1990). Similarly, avoidant students who procrastinate with their school work would have an excuse to avoid socializing with others.

While there are clear relationships among self-efficacy, procrastination, academic success, and attachment, there has not been any research looking at the possible mediation or moderation role of these factors. According to Baron and Kenny (1986) a moderator is often a quantitative or qualitative variable that affects either the strength or direction of the relationship between an independent and dependent variable. Meanwhile a mediator is a variable that actually accounts for (and explains why) the relationship between the predictor variable and the criterion (Baron \& Kenny, 1986). Thus, the goal of this study is to examine the possible role that both procrastination and self-efficacy have within the relationship between attachment and academic success and how it can be observed within the classroom setting.

\section{Method}

\subsection{Participants}

This study recruited students enrolled in a fall semester, morning section, Introductory Psychology course at a large northeastern university. There were 184 students who met together twice per week in a large lecture hall. In addition, the larger class was divided into eight recitation classes. Of the 184 students, 161 completed all of the required materials for the study. There were 59 males (37\%), 97 females (60\%), and 5 who did not report their gender $(3 \%)$. The average age was $19.3(\mathrm{SD}=2.98)$. In terms of ethnicity, $40(24.8 \%)$ were Asian/AsianAmerican, 35 (21.7\%) White/non-Hispanic, 27 (16.8\%) Hispanic/Latino (a), 18 (11.2\%) were Black/African American, 17 (10.6\%) Middle Eastern/Arabic/Persian, and 24 (14.9\%) defined themselves as other.

\subsection{Materials}

The students completed the following online surveys: the Experiences in Close Relationships (ECR-R) (Fraley, Waller, \& Brennan. 2000) which consists of 36 questions (18 measuring attachment anxiety and 18 measuring attachment avoidance) on a 5-point Likert scale, the General Self-Efficacy-Sherer (GSESH) questionnaire (Sherer, Maddux, Mercadante, Prentice-Dunn, Jacobs, \& Rogers, 1982) which consists of 12 questions on a 5-point Likert scale $(\alpha=.726)$, the Procrastination Assessment Scale-Students (PASS) (Solomon \& Rothblum, 1984) which consists of 18 questions on a 5-point Likert scale $(\alpha=.904)$. Likert Scales were from 1 (strongly disagree) to 5 (strongly agree).

\subsection{Procedure}

Students were required to complete all of the online surveys through a prescreening process at the beginning of the semester. At the end of the course, lecture and recitation measures of attendance and lateness were collected. Attendance was operationalized as whether the student came to class on a particular day. Students were marked late if they arrived more than fifteen minutes after the scheduled start of the class.

All students enrolled in the course were required to earn seven research points (R-points). Each student earns a specific number of points depending on the study for which they volunteer. At the end of the course, a list of all of the students' codes and the dates and times that they completed their R-point requirements was obtained. The date and time of the R-point completion was used to operationalize procrastination. Specifically, the first day of the semester was counted as day one.

In addition, during the second class of the semester, the instructor offered the students an optional extra credit assignment due prior to the first major exam. The assignment posted on Blackboard (Bb) was to read Milgram's Behavioral Study of Obedience (Milgram, 1963). The students were given an option of writing a two-page summary of the article (lower level of Bloom's Taxonomy; Bloom, 1956) or to write a five-page paper summarizing the article and asking the students to design a similar experiment (higher level of Bloom's Taxonomy) looking at obedience. Prior to the semester, a survey was created to ensure that the more difficult assignment was rated as such. A group of 32 students was asked to rate the difficulty of the two assignments. All 32 students rated the second option as being more challenging The students were told that the first option, if chosen, would be worth a maximum of two extra credit points and that the second option, if chosen, would be worth a maximum of five extra credit points. The article was available on $\mathrm{Bb}$ and if completed, was submitted through $\mathrm{Bb}$ as well. A list of the students who attempted each assignment and the grade earned on the assignment was e col- 
lected. The list also included the date and time stamp as to when the assignment was submitted. Students were identified by a code. Students' choice of assignment (easier or more difficult) was used to operationalize selfefficacy as it is believed that students high in self-efficacy would more readily attempt the more difficult assignment as they are more confident in their ability to successfully complete the assignment. Students who were low in self-efficacy were predicted to choose the easier assignment.

\subsection{Statistical Analysis}

For this study ANOVA, $t$-tests, correlational analysis, and regression analysis were used to test for relationships between variable and the effect of procrastination and self-efficacy had in mediating and/or moderating the relationship between attachment and academic success with the classroom.

\subsection{Hypothesis}

The main hypotheses involve testing whether self-efficacy or procrastination act as mediators or moderators for the relationship between attachment and academic success. Specific hypotheses are as follows:

1) Measures of attachment will correlate with measures of academic success. Specifically:

a) Students high in attachment anxiety will have lower final grades in the class and lower cumulative GPAs. GPAs.

b) Students high in attachment avoidance will have lower final grades in the class and lower cumulative

2) Measures of attachment will correlate with measures of procrastination and self-efficacy. Specifically:

a) Higher levels of attachment anxiety correlate with higher levels of procrastination and lower levels of self-efficacy.

b) Higher levels of attachment avoidance correlate with higher levels of procrastination and lower levels of self-efficacy.

3) Higher levels of procrastination will correlate with later R-point (research point) completion.

4) Measures of self-efficacy correlate with choosing to complete the more difficult extra credit assignment (to complete it at all and which assignment is chosen).

5) It is hypothesized that procrastination (as measured by R-point completion time) and/or self-efficacy (as measured with the self-efficacy survey) serve as a moderating factor within the relationship between attachment and academic success. Specifically:

a) Self-efficacy moderates the relationship between attachment anxiety and the students' final grade in their class.

b) Self-efficacy moderates the relationship between attachment anxiety and the students' cumulative GPA.

c) Self-efficacy moderates the relationship between attachment avoidance and the students' final grade in their class. GPA.

d) Self-efficacy moderates the relationship between attachment avoidance and the students' cumulative

e) Procrastination moderates the relationship between attachment anxiety and the students' final grade in their class.

f) Procrastination moderates the relationship between attachment anxiety and the students' cumulative GPA.

g) Procrastination moderates the relationship between attachment avoidance and the students' final grade in their class.

h) Procrastination moderates the relationship between attachment avoidance and the students' cumulative GPA.

6) It is hypothesized that self-efficacy (as measured with the self-efficacy survey) and/or procrastination (as measured by R-point completion time) can serve as a mediating factor within the relationship between attachment and academic success. Specifically:

a) Self-efficacy mediates the relationship between attachment anxiety and the students' final grade in their class and the students' cumulative GPA.

b) Self-efficacy mediates the relationship between attachment avoidance and the students' final grade in their class and the students' cumulative GPA. 
c) Procrastination mediates the relationship between attachment anxiety and the students' final grade in their class and the students' cumulative GPA.

d) Procrastination mediates the relationship between attachment avoidance and the students' final grade in their class and the students' cumulative GPA.

\section{Results}

Hypothesis 1 stated that measures of attachment would correlate with measures of academic success. Table 1 shows that students high in attachment anxiety had lower final grades in the class ( $r=.161, p=.041$ ), but did not have lower cumulative GPAs $(r=.111, p=.162)$ while students high in attachment avoidance had lower final grades in the class $(r=.157, p=.047)$ and lower cumulative GPAs $(r=.252, p=.001)$.

Hypothesis 2 stated that measures of attachment would be correlated with procrastination and self-efficacy. Table 1 shows that students high in attachment anxiety also had higher levels of procrastination $(r=.202, p$ $=.010)$ and low levels of self-efficacy $(r=-.195, p=.013)$. However, the results indicated that students high in attachment avoidance did not have higher procrastination scores $(r=.117, p=.140)$ nor measures of lower self-efficacy $(r=.098, p=.217)$.

Our third hypothesis stated that measures of procrastination would correlate with measures of R-point completion. Students who scored high in procrastination also took longer to compete their R-point requirements $(r=.192, p=.015)$. High and low levels of procrastination were determined by examining all students who were one standard deviation above and below the mean. This second analysis (Figure 1) also showed that students scoring high in procrastination took longer to complete their R-point requirements $[t(1,158)=$ 2.094, $p=.038]$.

Hypothesis 4 stated that measures of self-efficacy would correlate with the choice of extra credit assignment. There was no correlation between students high in self-efficacy and whether or not they chose to complete the

Table 1. Correlational analysis of major variable $(n=161)$.

\begin{tabular}{|c|c|c|c|c|c|c|c|c|}
\hline & \multicolumn{8}{|c|}{ Correlations } \\
\hline & Avoidance & Procrast & Self-efficacy & Final grade & $\mathrm{PA}$ & $\begin{array}{l}\text { Assignment } \\
\text { completion }\end{array}$ & $\begin{array}{c}\text { Assignment } \\
\text { chosen }\end{array}$ & $\begin{array}{c}\mathrm{R} \text { point } \\
\text { completion }\end{array}$ \\
\hline Anxiety & $-.301^{* *}$ & $202^{*}$ & $-.195^{*}$ & $-.161^{*}$ & -.111 & -.004 & 021 & .096 \\
\hline Avoidance & & 117 & -.098 & $-.157^{*}$ & $-.252^{* *}$ & .079 & .190 & .101 \\
\hline Procrast & & & $-.160^{*}$ & -.111 & $-.190^{*}$ & .002 & .166 & $.192^{*}$ \\
\hline Self-efficacy & & & & $.209^{* *}$ & $.255^{* *}$ & -.016 & .283 & -.154 \\
\hline Final grade & & & & & .032 & $-.339^{* *}$ & .062 & $-.315^{* *}$ \\
\hline GPA & & & & & & -.059 & .208 & -.107 \\
\hline $\begin{array}{l}\text { Assignment } \\
\text { completion }\end{array}$ & & & & & & & .164 & .086 \\
\hline $\begin{array}{l}\text { Assignment } \\
\text { chosen }\end{array}$ & & & & & & & & -.167 \\
\hline
\end{tabular}

${ }^{*} p<.05,{ }^{* *} p<.01$.

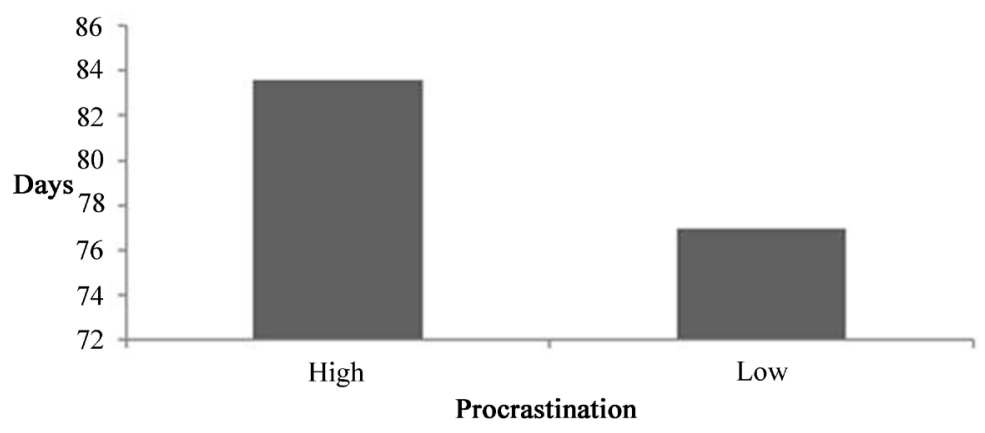

Figure 1. Days needed to complete R-points by level of procrastination. 
extra credit assignment $(r=.016, p=.839)$. There was also no correlation between high levels of self-efficacy and which assignment (easy or hard) was chosen $(r=.283, p=.105)$. Although a one-way ANOVA showed no significant difference between students who did not attempt the extra credit assignment, those that chose the easier assignment, and those who chose the harder assignment $[F(2,158)=.898, p=.409]$, there was a trend for students high in self-efficacy to attempt the more difficult extra credit assignment (see Figure 2$)[t(1,32)=$ $1.711, p=.098]$.

The fifth hypothesis stated that procrastination and/or self-efficacy would serve as a moderating factor within the relationship between attachment and academic success. To test for moderation, hierarchical multiple regression analysis (Baron \& Kenny, 1986) was used to examine the effect of the moderators (procrastination and selfefficacy) on the relationship between attachment (measured by attachment anxiety and attachment avoidance scales) and academic success (measured by final grade and GPA). For each test of moderation a new variable was created by multiplying the attachment measure by the proposed moderator. As there are two proposed attachment measurements and two proposed moderators, four new variables were created (attachment anxiety $\times$ procrastination, attachment anxiety $\times$ self-efficacy, attachment avoidance $\times$ procrastination, attachment avoidance $\times$ self-efficacy). After the new variable(s) was created, a two-step regression analysis was performed. For each hypothesis, first a regression analysis was conducted using both the attachment measurement and the moderator as the independent variable and the predicted dependent variable (final grade and cumulative GPA) as the dependent variable. Second, a regression analysis was performed using the attachment measurement, the moderator, and the new interactive variable (for each attachment measure and moderator), and the predicted dependent variable (final grade and cumulative GPA) as the dependent variable. Once completed the relationship between the new variable and the dependent variable was checked for significance. To avoid a type II error, a level of significance of .1 has been used to test for significance.

Of the eight proposed hypotheses, five were significant (hypothesis a, b, d, f, h), and three were not significant (hypothesis c, e, g). Specifically, hypothesis 5a was supported; self-efficacy moderated the relationship between attachment anxiety and the students' final grades in their class (see Table 2). The results of this test were significant (see Figure 3). The simple slope of the high self-efficacy is $t=.211(p=.833$ ) and the simple

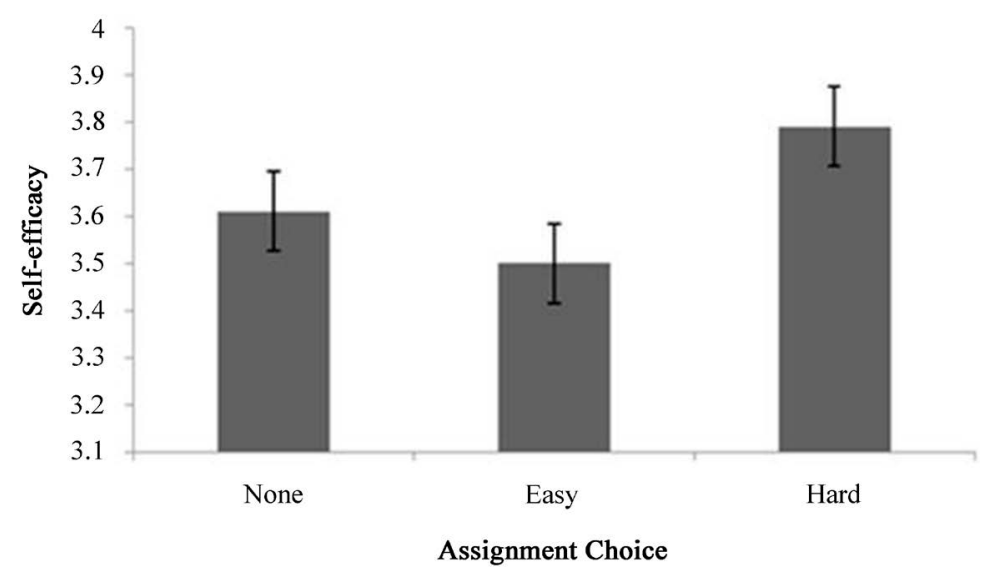

Figure 2. Level of self-efficacy as a product of level of difficulty of assignment chosen.

\begin{tabular}{cccccc}
\multicolumn{5}{l}{ Table 2. Hierarchal multiple regression analysis of attachment anxiety and self-efficacy on final grade. } \\
\hline \multicolumn{1}{c}{1} & $\mathrm{~b}$ & $\mathrm{SE}$ & $\beta$ & $\mathrm{Sig}$ \\
\hline & Anxiety & -1.300 & .820 & -.125 & .115 \\
& Self-efficacy & 2.775 & 1.180 & .185 & .020 \\
& Anxiety & -.940 & .833 & -.090 & .261 \\
& Self-efficacy & 1.986 & 1.239 & .132 & .111 \\
& Anxiety $\times$ self-efficacy & 1.789 & .922 & .163 & .054 \\
\hline
\end{tabular}

Note: $R^{2}$ change from .059 to .081 
slope for the low self-efficacy is $t=-2.316(p=.022)$.

Hypothesis $5 \mathrm{~b}$ stated that self-efficacy would moderate the relationship between attachment anxiety and the students' cumulative GPA (see Table 3). This relationship was significant (see Figure 4). The simple slope of the high self-efficacy is $t=1.498(p=.050)$ and the simple slope for the low self-efficacy is $t=-1.906(p=.052)$.

Hypothesis $5 \mathrm{~d}$ stated that self-efficacy would moderate the relationship between attachment avoidance and students' cumulative GPA (see Table 4) and it did (see Figure 5). The simple slope of the high self-efficacy is $t$ $=.436(p=.558)$ and the simple slope for the low self-efficacy is $t=-4.127(p=.000)$.

Hypothesis $5 \mathrm{f}$ stated that procrastination would moderate the relationship between attachment anxiety and the students' cumulative GPA (see Table 5). The results of this test were significant (see Figure 6). The simple slope of the high procrastination is $t=-3.159(p=.002)$ and the simple slope for the low self-efficacy is $t=$ $3.109(p=.014)$.

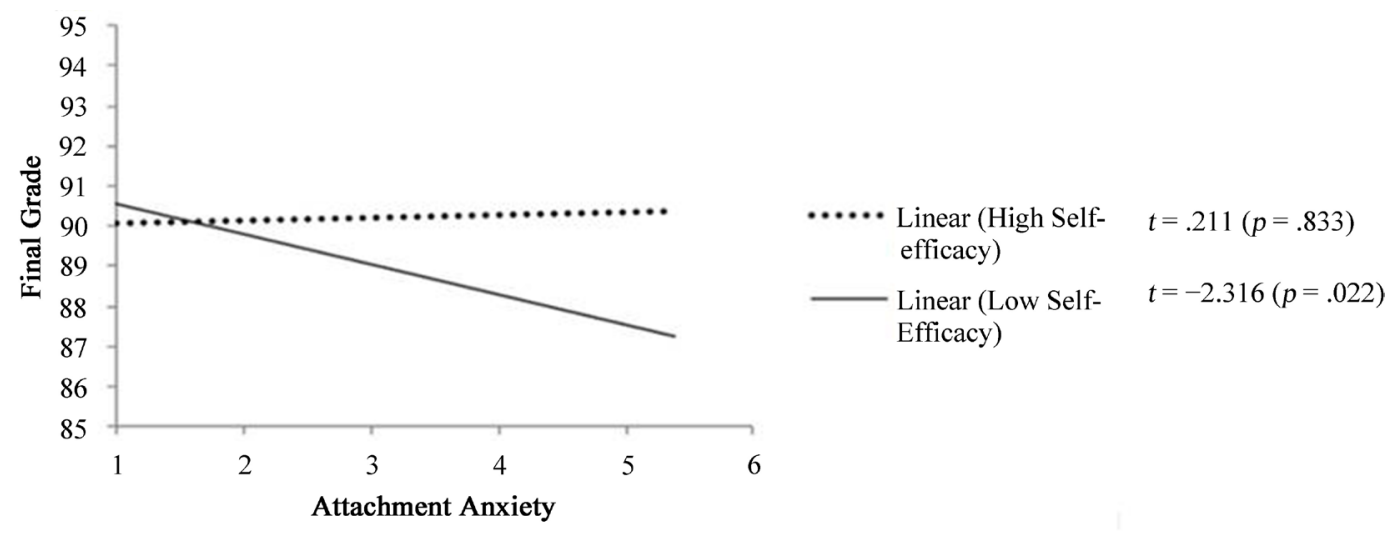

Figure 3. Final grade as a function of attachment anxiety and self-efficacy.

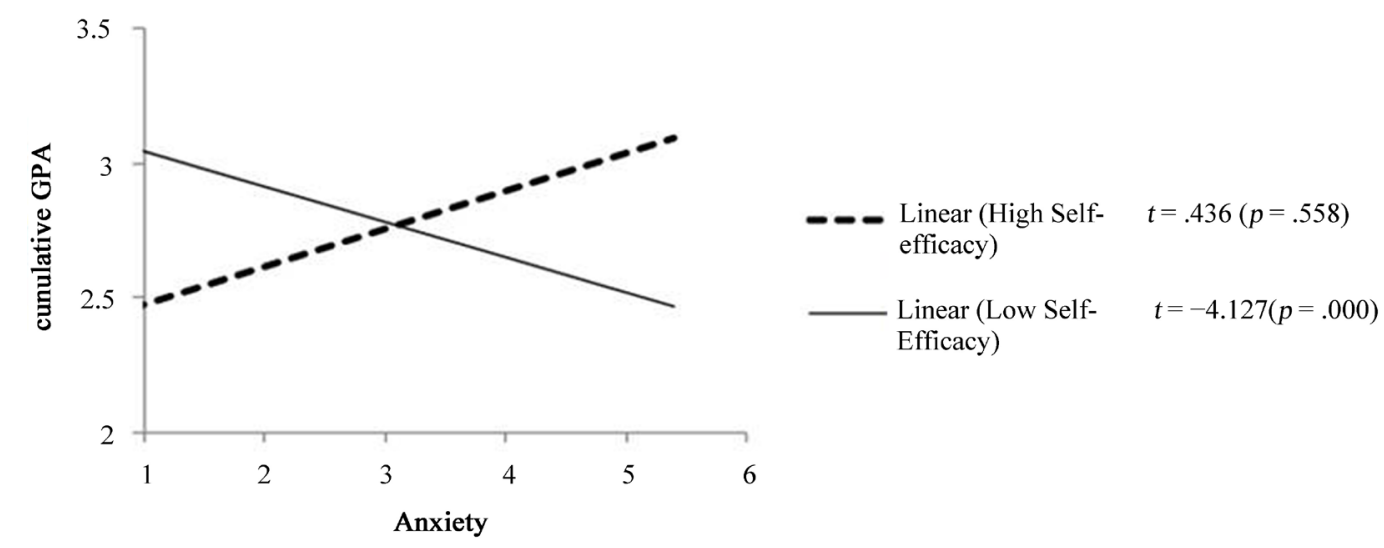

Figure 4. Cumulative GPA as a function of attachment anxiety and self-efficacy.

Table 3. Hierarchal multiple regression analysis of attachment anxiety and self-efficacy on cumulative GPA.

\begin{tabular}{cccccc}
\hline & & $\mathrm{b}$ & $\mathrm{SE}$ & $\beta$ & Sig \\
\hline 1 & Anxiety & -.055 & .068 & -.063 & .420 \\
& Self-efficacy & .303 & .098 & .242 & .002 \\
& Anxiety & .000 & .067 & .000 & .998 \\
& Self-efficacy & .182 & .100 & .146 & .070 \\
& Anxiety $\times$ self-efficacy & .274 & .074 & .300 & .000 \\
\hline
\end{tabular}

Note: $R^{2}$ change from .069 to .143 . 
Table 4. Hierarchal multiple regression analysis of attachment avoidance and self-efficacy on cumulative GPA.

\begin{tabular}{cccccc}
\hline & & $\mathrm{b}$ & $\mathrm{SE}$ & $\beta$ & Sig \\
\hline 1 & Anxiety & -.373 & .123 & -.229 & .003 \\
& Self-efficacy & .291 & .094 & .232 & .002 \\
& Anxiety & -.290 & .123 & -.178 & .020 \\
& Self-efficacy & .186 & .099 & .148 & .063 \\
& Anxiety $\times$ self-efficacy & .339 & .119 & .231 & .005 \\
\hline
\end{tabular}

Note: $R^{2}$ change from .117 to .160 .

Table 5. Hierarchal multiple regression analysis of attachment anxiety and procrastination on cumulative GPA.

\begin{tabular}{cccccc}
\hline & & $\mathrm{b}$ & $\mathrm{SE}$ & $\beta$ & \multicolumn{2}{c}{ Sig } \\
\hline 1 & Anxiety & -.065 & .069 & -.075 & .345 \\
2 & Procrastination & -.200 & .091 & -.175 & .029 \\
& Anxiety & .630 & .229 & .725 & .007 \\
& Procrastination & -.159 & .089 & -.139 & .076 \\
& Anxiety $\times$ procrastination & -.237 & .075 & -.843 & .002 \\
\hline
\end{tabular}

Note: $R^{2}$ change from .042 to .099 .

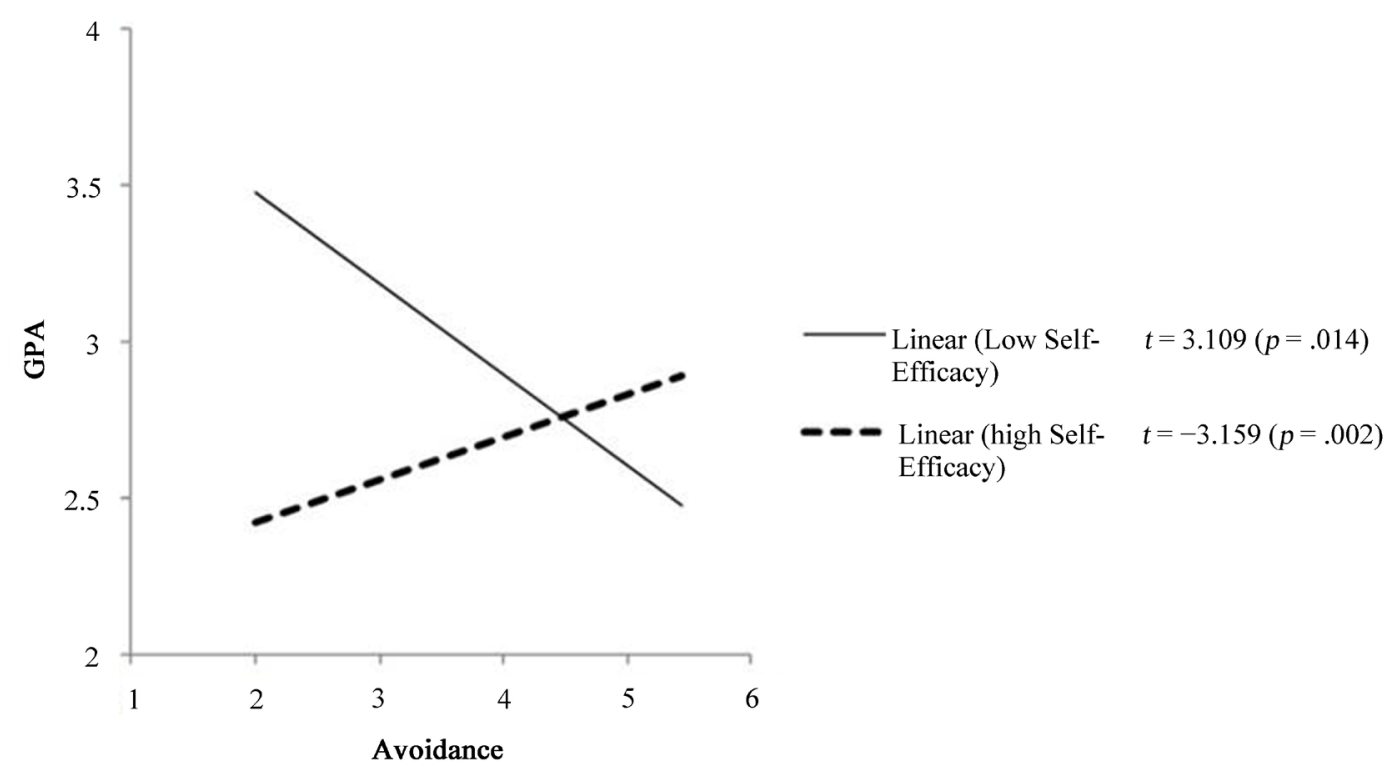

Figure 5. Cumulative GPA as a function of attachment avoidance and self-efficacy.

Hypothesis 5h stated that procrastination would moderate the relationship between attachment avoidance and the students' cumulative GPA (see Table 6). The results of this test were significant (see Figure 7). The simple slope of the high procrastination is $t=-3.767(p=.000)$ and the simple slope for the low self-efficacy is $t=$ $-2.419(p=.017)$.

Hypothesis 5c stated that self-efficacy would moderate the relationship between attachment avoidance and the students' final grades in their class. The results of this test were not significant. Procrastination was hypothesized to moderate the relationship between attachment anxiety (5e) and attachment avoidance (5g) and the students' final grades in their class; neither relationship was significant.

Hypothesis 6 stated that procrastination and/or self-efficacy serves as a mediating factor within the relation- 


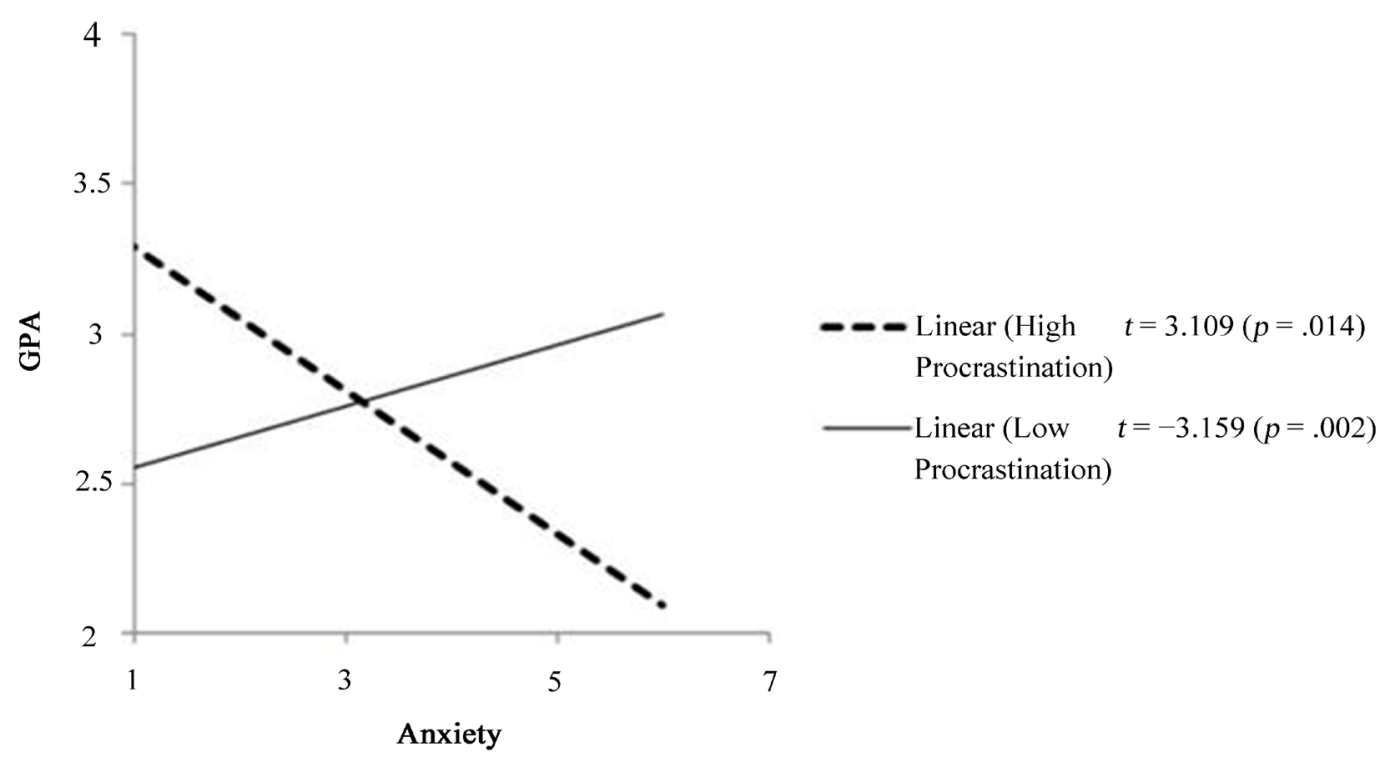

Figure 6. Cumulative GPA as a function of attachment anxiety and procrastination.

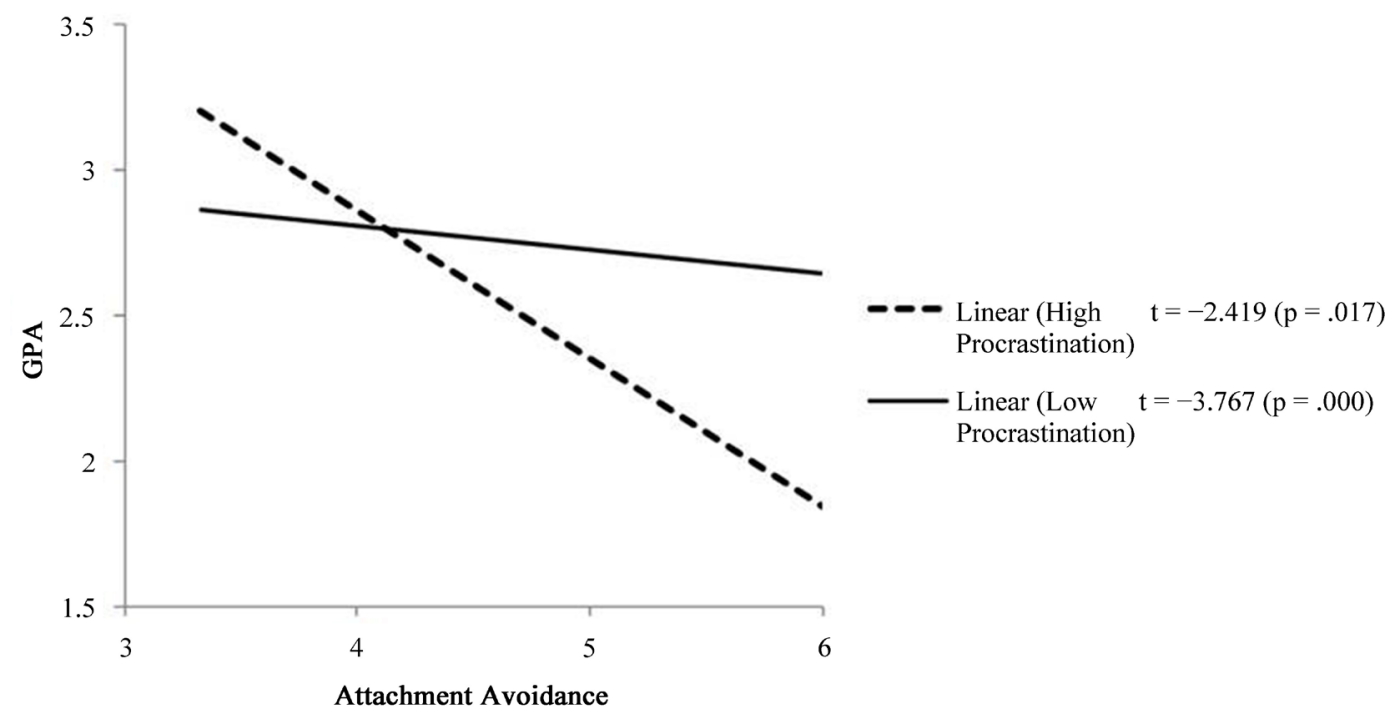

Figure 7. Cumulative GPA as a function of attachment avoidance and procrastination.

Table 6. Hierarchal multiple regression analysis of attachment avoidance and procrastination on cumulative GPA.

\begin{tabular}{|c|c|c|c|c|c|}
\hline & & $\mathrm{b}$ & SE & $\beta$ & sig \\
\hline \multirow[t]{2}{*}{1} & Anxiety & -.379 & .125 & -.233 & .003 \\
\hline & Procrastination & -.187 & .087 & -.163 & .034 \\
\hline \multirow[t]{3}{*}{2} & Avoidance & .191 & .332 & .117 & .567 \\
\hline & Procrastination & -.182 & .087 & -.159 & .038 \\
\hline & Anxiety $\times$ procrastination & -.191 & .103 & -.377 & .066 \\
\hline
\end{tabular}

Notes: $R^{2}$ change from .090 to .109 . 
ship between attachment and academic success. In testing for mediation using the steps outlined by Baron and Kenny (1986), the operationalized variable for procrastination (R-point completion time) and self-efficacy (choice of extra credit assignment) were used. For this study, none of the eight hypotheses involving mediation was supported. For each of the hypotheses, there was no significance in the first three steps of the process.

\section{Discussion}

The current results show that higher levels of either attachment anxiety or attachment avoidance were related to students' lower final grades. Students who indicated that they had high levels of attachment anxiety had high levels of procrastination and low levels of self-efficacy. However, there was no correlation between attachment avoidance and measures of procrastination or self-efficacy. Attachment avoidance, however, was related to students' overall lower cumulative GPA.

A main purpose of this study was to determine if procrastination and/or self-efficacy moderated the relationship between attachment and academic success. There is a strong indication that both procrastination and selfefficacy do have moderating effects. Specifically, in terms of attachment anxiety, self-efficacy moderated the relationship with final grade and cumulative GPA.

For students who are low in self-efficacy, those with higher levels of attachment anxiety have lower final grades while for students high in self-efficacy, attachment anxiety has no effect on their final grade. In terms of the results regarding cumulative GPA, similar to the final grade, for students who are low in self-efficacy, their cumulative GPA is lower when their attachment anxiety is lower. However, for students high in self-efficacy, while their attachment anxiety is higher, so is their GPA.

For students with high levels of self-efficacy, attachment anxiety appears to be of lesser importance overall in academic success. Perhaps high self-efficacy is able to cancel out the negative effects of high attachment anxiety. It may also be that attachment anxiety has more of an effect on an individual class as compared to an overall GPA as there are so many more factors that affect a student over the course of their enrollment at college as compared to a four-month period within one class. There also could be some effect regarding the type of class in which the students enrolled. Perhaps when it comes to performance in a psychology class, students are more focused with the content. Taking a psychology class may permit students to look further into themselves as they study a variety of topics that are used to examine how people think behave, and feel. Possibly students high in self-efficacy are able to neutralize the contribution of high anxiety or are able to better explore and maneuver around their own psychological needs and be more successful. This psychology course is not a required course, but instead is an elective chosen by many students. They may have selected the course as they feel more confident in their ability to be successful within the class.

Self-efficacy also was shown to be a moderator of GPA and attachment avoidance. Similar to the results with attachment anxiety, high levels of self-efficacy may have prevented a student's insecure (avoidant) attachment from negatively affecting their GPA. As this has been the case for both individuals with high attachment anxiety and attachment avoidance, perhaps high levels of self-efficacy can actually contradict the effects of attachment insecurity on academic success. As per Schunk and Pajares (2002), self-efficacy is comprised of a variety of components that include one's perception of own ability (i.e. self-assessment). Therefore, a high level of selfefficacy may have been created from a positive view of self, a key component of a secure attachment. In addition, the majority of students in the psychology course are in their first year of college and thus maybe being accepted into college has an effect on their overall self-efficacy.

Two results also support the hypothesis that procrastination moderates the relationship between attachment and academic success (in terms of cumulative GPA). For insecurely attached students (those high in attachment avoidance and those high in attachment anxiety), high levels of procrastination were strongly related to lower GPA's. It would seem that attachment avoidance has a detrimental effect for students with high levels of procrastination, which lead to lower GPA's. If one is high on attachment avoidance, they may study alone more often and lose the ability to have peer support and assistance in preparing for exams or completing assignments. If they are also high on procrastination, they might leave too much information to learn for the very last minute. A study group might help them deal with this problem, but these individuals would prefer to prepare individually.

Students high in attachment anxiety may, on the other hand, seek out others with whom to study. If they are also high on procrastination, they may wait to study until they are with others, leaving them more susceptible to having poorer individual study habits and wanting to wait for others to assist them. In contrast, if an avoidant 
student (characterized by having a negative view of others) felt confused or unclear about a topic or problem and needed help, he/she may be less willing to approach a fellow classmate or professor. That coupled with high procrastination may cause them to delay finding the help they need until it is too late. Similarly, students high in attachment anxiety (characterized by having a negative view of self) may also not feel comfortable approaching a professor or another student as it would be putting themselves under scrutiny. They would not want to appear as if they are unsure or confused as it may further support their negative view of self. If the students are also high in procrastination, similar to the avoidant students, they may delay getting the help they need.

R-point completion was used to operationalize procrastination. There was a strong positive relationship between levels of procrastination and time it took to complete the R-point requirements. This may indicate that R-point requirements are a good indicator of one's tendency to procrastinate. The results also indicated a weak relationship between self-efficacy and choice of extra credit assignment. While the results were not significant, students who scored higher in self-efficacy were more willing to attempt the more challenging assignment. It is possible that if an individual has high levels of self-efficacy, then that would foster more confidence in one's ability to succeed on a more difficult assignment.

One of the main hypotheses tested whether procrastination or self-efficacy served as a mediator in the relationship between attachment and student academic success. Using the measures of R-point completion for procrastination and the measures of extra credit assignment attempted for self-efficacy, the results did not support these hypotheses. R-point completion was considered a good indicator of procrastination. However, there were other intervening factors as well. For example, R-point completion is not necessarily a precise measure. In attempting to complete the required R-points, some of the ability to complete the R-points is within one's control, and some is not. If a researcher who is leading a particular project does not schedule his/her session until late in the semester, then a student's R-point completion may in reality have no relation to levels of procrastination. Or it may also be that students with certain qualities (as determined in the prescreening process) are not the right fit for a particular research project being conducted and therefore may not be selected in a timely fashion, again causing a delay in their ability to complete their R-point requirements. It may also be that a project that a student has signed up for will not award R-points until late in the semester (i.e., if a research project requires a student to return later in the semester). Therefore, perhaps a better indicator of procrastination would be to record when the student signs up for the experiment instead of when it was actually completed.

Self-efficacy, procrastination, and attachment all play a role in students' academic success. Specifically, procrastination and self-efficacy have been shown to moderate the relationship between attachment and academic success. By finding ways to increase students' self-efficacy and decrease their procrastination tendencies, attachment insecurity may have less of an effect on student success and thus lead to higher levels of academic success. An argument could be made that self-efficacy, as operationalized by the choice of extra credit assignment, may not be a good measurement. While there seemed to be a trend in the relationship between selfefficacy and extra credit choice, it was not significant. Other factors could be at play. One could argue that if an individual is high in self-efficacy, then perhaps he or she feels very confident with their ability to successfully pass the course. Therefore, they will not feel the need to attempt the extra credit assignment, or, if attempted, may not feel the need to attempt the more difficult assignment.

\section{References}

Ainsworth, M. D. S., Blehar, M. C., Waters, E., \& Wall, S. (1978). Patterns of Attachment: A Psychological Study of the Strange Situation. Hillsdale, NJ: Erlbaum.

Akinsola, M. K., Tella, A., \& Tella, A. (2007). Correlates of Academic Procrastination and Mathematics Achievement of University Undergraduate Students. Eurasia Journal of Mathematics, Science \& Technology Education, 3, 363-370.

Aspelmeier, J., \& Kerns, K. (2003). Love and School: Attachment/Exploration Dynamics in College. Journal of Social \& Personal Relationships, 20, 5-30. http://dx.doi.org/10.1177/02654075030201001

Bandura, A. (1986). Social Foundations of Thought and Action: A Social Cognitive Theory. Englewood Cliffs, NJ: Prentice Hall.

Bandura, A. (1997). Self-Efficacy: The Exercise of Control. New York: Freeman.

Baron, R. A., \& Byrne, D. (2003). Social Psychology (10 ${ }^{\text {th }}$ ed.). New York: Pearson Education, Inc.

Baron, R. M., \& Kenny, D. A. (1986). The Moderator-Mediator Variable Distinction in Social Psychological Research: Conceptual, Strategies, and Statistical Considerations. Journal of Personality and Social Psychology, 6, 1173-1182.

http://dx.doi.org/10.1037/0022-3514.51.6.1173 
Bartholomew, K., \& Horowitz, L. M. (1991). Attachment Styles among Young Adults: A Test of a Four-Category Model. Journal of Personality and Social Psychology, 61, 226-244. http://dx.doi.org/10.1177/0743558403260096

Bernier, A., Larose, S., Boivin, M., \& Soucy, N. (2004). Attachment State of Mind: Implications for Adjustment to College. Journal of Adolescent Research, 19, 783-806. http://dx.doi.org/10.1177/0743558403260096

Bloom, B. S. (1956). Taxonomy of Educational Objectives: The Classification of Educational Goals. New York: Longmans, Green.

Bouffard-Bouchard, T., Parent, S., \& Larivee, S. (1991). Influence of Self-Efficacy on Self-Regulation and Performance among Junior and Senior High-School Age Students. International Journal of Behavioral Development, 14, 153-164. http://dx.doi.org/10.1177/016502549101400203

Brennan, K. A., \& Morris, K. A. (1997). Attachment Styles, Self-Esteem, and Patterns of Feedback Seeking from Romantic Partners. Personality and Social Psychology Bulletin, 23, 23-31. http://dx.doi.org/10.1177/0146167297231003

Burka, J. B., \& Yuen, L. M. (1983). Procrastination: Why You Do It What to Do about It. Cambridge, MA: Da Capo Press.

Corcoran, K. O., \& Mallinckrodt, B. (2000). Adult Attachment, Self-Efficacy, Perspective Taking, and Conflict Resolution. Journal of Counseling \& Development, 78, 473-483. http://dx.doi.org/10.1002/j.1556-6676.2000.tb01931.x

Courneya, K. S., \& McAuley, E. (1993). Efficacy, Attributional, and Affective Responses of Older Adults Following an Acute Bout of Exercise. Journal of Social Behavior and Personality, 8, 729-742.

Cutrona, C., Cole, V., Colangelo, N., Assouline, S., \& Russell, D. (1994). Perceived Parental Social Support and Academic Achievement: An Attachment Theory Perspective. Journal of Personality and Social Psychology, 66, 369-378.

http://dx.doi.org/10.1037/0022-3514.66.2.369

Davidovitz, R., Mikulincer, M., Shaver, P. R., Ijzak, R., \& Popper, M. (2007). Leaders as Attachment Figures: Their Attachment Orientations Predict Leadership-Related Mental Representations and Followers' Performance and Mental Health. Journal of Personality and Social Psychology, 93, 632-650. http://dx.doi.org/10.1037/0022-3514.93.4.632

Fass, M., \& Tubman, J. (2002). The Influence of Parental and Peer Attachment on College Students' Academic Achievement. Psychology in the Schools, 39, 561-573. http://dx.doi.org/10.1002/pits.10050

Fraley, R. C., Waller, N. G., \& Brennan, K. A. (2000). An Item-Response Theory Analysis of Self-Report Measures of Adult Attachment. Journal of Personality and Social Psychology, 78, 350-365. http://dx.doi.org/10.1037/0022-3514.78.2.350

Hazan, C., \& Shaver, P. (1990). Love and Work: An Attachment Theoretical Perspective. Journal of Personality and Social Psychology, 59, 270-280. http://dx.doi.org/10.1037/0022-3514.59.2.270

Klassen, R. M., Krawchuk, L. L., \& Rajani, S. (2008). Academic Procrastination of Undergraduates: Low Self-Efficacy to Self-Regulate Predicts Higher Levels of Procrastination. Contemporary Educational Psychology, 33, 915-931. http://dx.doi.org/10.1016/j.cedpsych.2007.07.001

Kurland, R. M., \& Siegel, H. I. (2013). Attachment and Student Success during the Transition to College. NACADA Journal, 33, 16-28. http://dx.doi.org/10.12930/NACADA-12-252

Larose, S., Bernier, A., \& Tarabulsy, G. M. (2005). Attachment State of Mind, Learning Dispositions, and Academic Performance during the College Transition. Developmental Psychology, 41, 281-289. http://dx.doi.org/10.1037/0012-1649.41.1.281

Linnenbrink, E. A., \& Pintrich, P. R. (2002). Motivation as an Enabler for Academic Success. School Psychology Review, 31, 313-327.

Maddux, J. E., \& Stanley, M. A. (1986). Self-Efficacy Theory in Contemporary Psychology: An Overview. Journal of Social and Clinical Psychology, 4, 249-255. http://dx.doi.org/10.1521/jscp.1986.4.3.249

Mallinckrodt, B., \& Wei, M. (2005). Attachment, Social Competencies, Social Support, and Psychological Distress. Journal of Counseling Psychology, 52, 358-367. http://dx.doi.org/10.1037/0022-0167.52.3.358

Mattanah, J. F., Hancock, G., \& Brand, B. L. (2004). Parental Attachment, Separation-Individuation, and College Student Adjustment: A Structural Equation Analysis of Mediational Effects. Journal of Counseling Psychology, 51, 213-225. http://dx.doi.org/10.1037/0022-0167.51.2.213

Meece, J. L. (1997). Child and Adolescent Development for Educators. New York: McGraw-Hill.

Mikulincer, M., \& Shaver, P. (2007). Attachment in Adulthood. New York: The Guilford Press.

Milgram, S. (1963). Behavior Study of Obedience. Journal of Abnormal and Social Psychology, 67, 371-378. http://dx.doi.org/10.1037/h0040525

Myers, D. (1989). Psychology (2nd ed.). New York: Worth Publishers Inc.

Pajares, F., \& Miller, M. D. (1994). The Role of Self-Efficacy and Self-Concept Beliefs in Mathematical Problem-Solving: A Path Analysis. Journal of Educational Psychology, 86, 193-203. http://dx.doi.org/10.1037/0022-0663.86.2.193

Pajares, F., \& Schunk, D. (2001). Self-Beliefs and School Success: Self-Efficacy, Self-Concept, and School Achievement. In 
R. J. Riding, \& S. G. Rayner (Eds.), International Perspectives on Individual Differences: Self-Perception (Vol. 2, pp. 239-265). Westport, CT: Ablex.

Parker, J. D. A., Summerfeldt, L. J., Hogan M. J., \& Majeski, S. A. (2004). Emotional Intelligence and Academic Success: Examining the Transition from High School to University. Personality and Individual Differences, 36, 163-172. http://dx.doi.org/10.1016/S0191-8869(03)00076-X

Pychyl, T. A., Morin, R. W., \& Salmon, B. R. (2000). Procrastination and the Planning Fallacy: An Examination of the Study Habits of University Students. Journal of Social Behavior and Personality, 15, 135-150.

Salas, E., Driskell, J. E., \& Hughes, S. (1996). Introduction: The Study of Stress and Human Performance. In J. E. Driskell, \& E. Salas (Eds.), Stress and Human Performance (pp. 1-47). Mahwah, NJ: Erlbaum.

Sanna, L. J., \& Pusecker, P. A. (1994). Self-Efficacy, Valence of Self-Evaluation, and Performance. Personality and Social Psychology, 20, 82-92. http://dx.doi.org/10.1177/0146167294201008

Schunk, D. H. (1995). Self-Efficacy, Motivation, and Performance. Journal of Applied Sport Psychology, 7, 109-134. http://dx.doi.org/10.1080/10413209508406961

Schunk, D. H., \& Pajares, F. (2002). The Development of Academic Self-Efficacy. In A. Wigfield, \& J. S. Eccles (Eds.), Development of Achievement Motivation (pp. 15-31). San Diego, CA: Academic Press. http://dx.doi.org/10.1016/B978-012750053-9/50003-6

Sherer, M., Maddux, J. E., Mercadante, B., Prentice-Dunn, S., Jacobs, B., \& Rogers, R. W. (1982). The Self-Efficacy Scale: Construction and Validation. Psychological Reports, 51, 663-671. http://dx.doi.org/10.2466/pr0.1982.51.2.663

Skowron, E. A., \& Dendy, A. K. (2004). Differentiation of Self and Attachment in Adulthood: Relational Correlates of Effortful Control. Contemporary Family Therapy, 26, 337-357. http://dx.doi.org/10.1023/B:COFT.0000037919.63750.9d

Solomon, L. J., \& Rothblum, E. D. (1984). Academic Procrastination: Frequency and Cognitive-Behavioral Correlates. Journal of Counseling Psychology, 31, 503-509. http://dx.doi.org/10.1037/0022-0167.31.4.503

Tracey, T. J., \& Sedlacek, W. E. (1985). The Relationship of Noncognitive Variables to Academic Success: A Longitudinal Comparison by Race. Journal of College Student Personnel, 26, 405-410.

Wei, M., Russell, D., \& Zakalik, R. (2005). Adult Attachment, Social Self-Efficacy, Self-Disclosure, Loneliness, and Subsequent Depression for Freshman College Students: A Longitudinal Study. Journal of Counseling Psychology, 52, 602614. http://dx.doi.org/10.1037/0022-0167.52.4.602

Zimmerman, B. J., \& Bandura, A. (1994). Impact of Self-Regulatory Influences on Writing Course Attainment. American Educational Research Journal, 31, 845-862. http://dx.doi.org/10.3102/00028312031004845

\section{Submit or recommend next manuscript to SCIRP and we will provide best service for you:}

Accepting pre-submission inquiries through Email, Facebook, Linkedin, Twitter, etc

A wide selection of journals (inclusive of 9 subjects, more than 200 journals)

Providing a 24-hour high-quality service

User-friendly online submission system

Fair and swift peer-review system

Efficient typesetting and proofreading procedure

Display of the result of downloads and visits, as well as the number of cited articles

Maximum dissemination of your research work

Submit your manuscript at: http://papersubmission.scirp.org/ 